
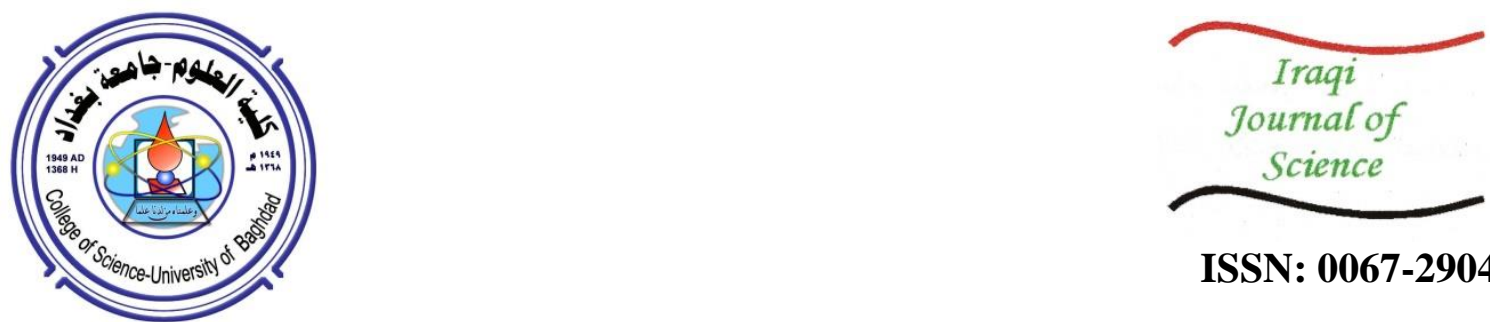

ISSN: 0067-2904

\title{
Establishment of Lipid Profile Reference Intervals in a Sample Population of Halabja City, Kurdistan Region of Iraq
}

\author{
Hardi Rafat Baqi ${ }^{1 *}$, Tareq Hamaamin Abdullah ${ }^{2}$, Dashty Aziz Ghafor ${ }^{3}$ Salar Husein \\ Karim ${ }^{4}$ \\ ${ }^{1,2}$ Medical Laboratory Techniques Department, Halabja Technical Institute | Research Center, Sulaimani \\ Polytechnic University, Halabja, Kurdistan region of Iraq \\ ${ }^{3,4}$ Laboratories Department, Halabja General Directorate of Health, Halabja, Kurdistan region of Iraq
}

$$
\text { Received: 4/10/2020 }
$$

Accepted: 7/2/2021

\begin{abstract}
Every laboratory needs to establish its own community-based reference intervals for the achievement of the optimal and true diagnosis in the clinical practice. However, such vital experimentations are not been conducted sufficiently in Halabja city and Kurdistan region of Iraq as a whole. This study is an attempt to introduce for the first time a set of reference intervals of lipid profile variables that are based on the healthy and asymptomatic adult population of Halabja using international standards. The methodology recruited for this purpose is based on the IFCC, CLSI, and WHO's standards, in which the study population was subjected to strict exclusion criteria for the sake of higher accuracy in the results. The reference intervals are computed as the 95th percentile of the lipid profile variable values. The results are broken down based on the gender and age groups. All of the estimated intervals fall perfectly in the internationally known reference intervals. Even so, the outcome values are similar and sometimes higher than the currently used intervals by the laboratories and physicians for the diagnosis purposes. The out-turns from the study encourage us to demand the healthcare providers to reconsider the currently approved reference intervals for the lipid profile test (TC, TG, HDL-C, LDL-C, and VLDL-C) in the clinical practice and consider the results of this study for further diagnostic purposes.
\end{abstract}

Keywords: Reference intervals, Lipid profile, Total cholesterol, Triglycerides, High-Density Lipoprotein cholesterol, Low-Density Lipoprotein cholesterol, Very Low-Density Lipoprotein cholesterol

\section{تأسيس الفواصل المرجعية لمستوى الدهون في مدينة حلبجة بأقليم كوردستان العرقق}

\author{
هلردى رفعت باقى 1*، طارق حمهامين عبدالله، دهشتى عزيز غفور²، سالار حسين كريم2 2

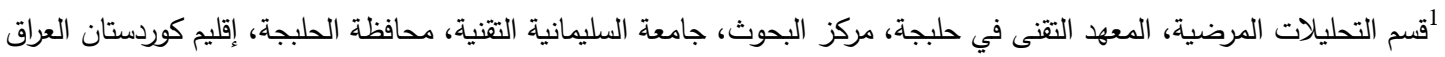

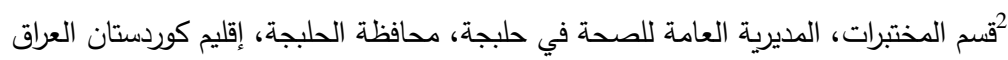

الخلاصة

كل مختبر يلزمه تأسيس فواصل مرجعية للمجتمع المحلى الخاص به لتأمين وانجاز التثخيص الصحيح

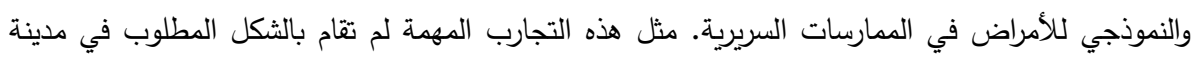

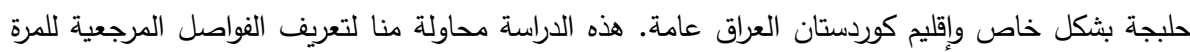

*Email: hardi.baqi@spu.edu.iq 


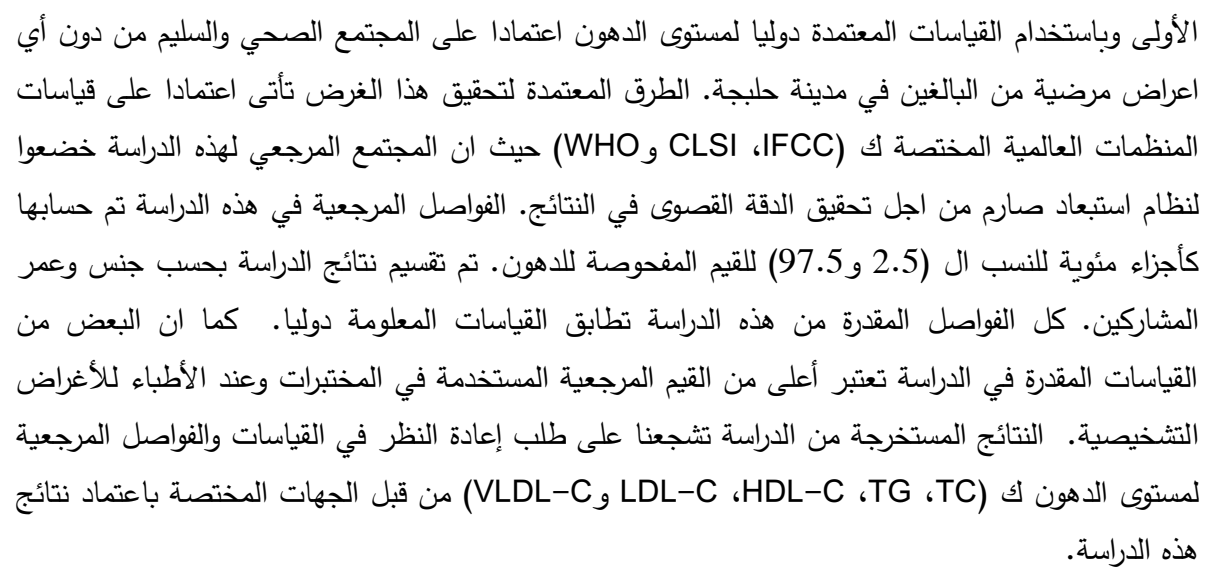

\section{Introduction}

Reference intervals are numerical tools used in clinical practice to diagnose, interpret, or estimate the progress of diseases. The method works by comparing the test results to the reference intervals. However, the quality of the reference intervals plays a major role in the final estimation and decision making [1]. The reference intervals for most of the tests in clinical diagnosis practice in Kurdistan region of Iraq as a whole and Halabja city in particular are those provided by the test kit manufacturer companies and international-based reference intervals. However, reference ranges of most tests, including the lipid profile test, are widely varying between different communities based on many factors, including race, ethnicity, gender, geographical location, and even the rural and urban area inhabitants [2]. From this viewpoint, the importance of possessing locally established normal intervals emerges. Lipids are biomolecules that have a hydrophobic nature and exert roles in energy storage, cell membrane structure, and signalling in human body [3]. Since dyslipidaemia, atherosclerosis and coronary artery disease (CAD) are accountable for most death numbers worldwide [4-6], understanding and evaluating lipid profile on a locally based distribution is crucial in clinical practice. Many researchers conducted their studies for the sake of evaluating the reference intervals of lipid profile and determine the higher risk groups for developing cardiovascular disease (CVD) in their local communities [7-10]. Yet, such studies are missing in Kurdistan region of Iraq. The reasoning behind conducting this study is sourced from the previously discussed background in order to show the normal distribution pattern of lipid profile according to gender and age groups in Halabja city's adult population.

\section{Materials and Methods}

\section{Inclusion and exclusion criteria}

This study is designed and conducted as a cross-sectional research that contained healthy asymptomatic adults in Halabja city from June to August 2019. All procedures were conducted after obtaining informed consent from the reference individuals who all signed permissions for using their data anonymously in our study. The study population comprises 451 adults aged 18-60 years, including $291(64.5 \%)$ males and $160(35.5 \%)$ females. The mean age of all subjects is $35.81 \pm 8.807$ years. They were all among the public employee staff of governmental organizations in the city centre of Halabja. To find any possible variation in the distribution of the lipid profile test variables, the subjects were classified according to age groups (<20, 21-30, 31-40, 41-50, 51-60 years old). The sample population was subjected to the International Federation of Clinical Chemistry (IFCC) exclusion criterion that eliminates anyone who has chronic diseases, including hypertension, CVD, diabetes, renal diseases, liver diseases, smokers, and alcohol takers [9]. Subjects with BMI $>30 \mathrm{~kg} / \mathrm{m}^{2}$ were also excluded, while the mean value of BMI among all participants was $25.3 \pm 2.819 \mathrm{~kg} / \mathrm{m}^{2}$. Only asymptomatic healthy adults were considered in the final results of this study.

\section{Sampling and biochemical assessments}

The specimens were collected in the mornings from the healthy adults using $5 \mathrm{~mL}$ sterilized syringes after ensuring that the participants were in 10-12 hours overnight fasting state. The withdrawn venepuncture blood was then transferred into gel separating test tubes and left until clotted. Then, the test tubes were centrifuged for 10 minutes at 3800 RPM. A clear yellow serum was obtained from the process and poured into Eppendorf tubes using a micropipette. Lipid profile tests were performed immediately afterwards, including total cholesterol, triglycerides, low-density lipoprotein 
cholesterol, high-density lipoprotein cholesterol, and very low-density lipoprotein cholesterol, using biochemical analyser (Roche Cobas-C111). The reagent kits for all tests were obtained from Roche Diagnostics. Anthropometry measurements of participants were taken by using an electronic body scale balance (TCS-200-RT), then the BMI was calculated [10].

\section{Statistical analysis}

The statistical analysis application SPSS (IBM SPSS statistics 26) was employed for analysing the data. Since the data were not normally distributed and skewed (non-Gaussian), the data were converted using a logarithmic transformation that helped in normalizing the distribution of the data. The outlined numbers after logarithmic transformations of the data were removed for securing a higher accuracy of the results. The mean values from the logarithmically transformed data were computed, then 2.5 and 97.5 percentiles of the data were calculated as a reference interval for all variables. The transformed results were finally converted into numerical values by taking antilog and the reference intervals were determined. This method for the determination of reference intervals is mostly recommended by IFCC [11]. An independent sample $t$-test was used for comparing the mean lipid profile values between the genders of participants. One-way ANOVA was recruited for finding significant variations among different age groups. The SPSS descriptive statistics and frequencies were used for viewing the data in a convenient way. The results are presented using APA style. The differences were considered statistically significant at $\mathrm{p}$-value lower than 0.05 .

\section{Results}

The data obtained from the study are presented using categorical methods for a better understanding of the distribution patterns of lipid profile variables in the sample population (Table- 1). The results show the distribution of the TC, TG, HDL-C, LDL-C, and VLDL-C according to gender. The mean values for each group show a slight increase in the mean values of TC, TG, and LDL-C variables in females compared with males. The difference in mean values between the two gender groups is statistically significant in TC and LDL-C, with a p-value of .007 and .049, respectively. Yet, the difference in TG mean values is not statistically significant, with a p-value greater than 0.05 . The mean values of HDL-C and VLDL-C in both genders are close to each other with no significant differences. The median values in almost all variables are close to the mean values, except for TG where they are different from each other. The closeness between mean and median values indicates the normality of the distribution of our data. The $95^{\text {th }}$ percentile for all variables is calculated by taking 2.5 and 97.5 percentiles. These values are considered as the reference intervals for the reference population of the study. The reference intervals of female individuals are higher than those of their male counterparts in all of the lipid profile variables. The new gender-based reference interval values for all variables allocate nearly in the defined reference intervals internationally.

Table 1-The calculated Mean $\pm \mathrm{SD}$, Median, 2.5 and 97.5 percentile, minimum, maximum and independent sample t-test significance values of the lipid profile variables (TC, TG, HDL-C, LDL-C, and VLDL-C; $\mathrm{mg} / \mathrm{dL}$ ) according to the gender of the reference population.

\begin{tabular}{|c|c|c|c|c|c|c|c|c|c|}
\hline & Gender & $\mathbf{N}$ & $\begin{array}{c}\text { Mean } \pm \\
\text { SD }\end{array}$ & Median & $\begin{array}{c}2.5 \\
\text { Percentile }\end{array}$ & $\begin{array}{c}97.5 \\
\text { Percentile }\end{array}$ & Minimum & Maximum & $\begin{array}{c}p- \\
\text { value }\end{array}$ \\
\hline \multirow{2}{*}{ TC } & $\mathrm{M}$ & 283 & $\begin{array}{c}163.37 \pm \\
32.77\end{array}$ & 159 & 107.2 & 236.8 & 97 & 296 & \multirow{2}{*}{.007} \\
\hline & $\mathrm{F}$ & 152 & $\begin{array}{c}172.32 \pm \\
34.52\end{array}$ & 169.5 & 110.85 & 251.22 & 100 & 257 & \\
\hline \multirow{2}{*}{ TG } & M & 249 & $\begin{array}{c}120.45 \pm \\
51.6\end{array}$ & 105 & 48.32 & 241.22 & 34 & 248 & \multirow{2}{*}{.247} \\
\hline & $\mathrm{F}$ & 116 & $\begin{array}{c}126.69 \pm \\
51.08\end{array}$ & 119 & 58.95 & 246 & 52 & 248 & \\
\hline \multirow{2}{*}{$\begin{array}{c}\text { HDL- } \\
\text { C }\end{array}$} & M & 285 & $\begin{array}{c}40.89 \pm \\
9.21 \\
\end{array}$ & 40 & 25 & 60.55 & 22 & 75 & \multirow{2}{*}{.774} \\
\hline & $\mathrm{F}$ & 156 & $\begin{array}{c}40.63 \pm \\
9.32 \\
\end{array}$ & 39 & 26.97 & 61.1 & 25 & 76 & \\
\hline \multirow[t]{2}{*}{ LDL-C } & M & 281 & $\begin{array}{c}101 \pm \\
25.8 \\
\end{array}$ & 99 & 58.35 & 159.95 & 50 & 178 & \multirow[t]{2}{*}{.049} \\
\hline & $\mathrm{F}$ & 152 & $106.08 \pm$ & 104.5 & 63.7 & 164.3 & 54 & 174 & \\
\hline
\end{tabular}




\begin{tabular}{|c|c|c|c|c|c|c|c|c|c|}
\hline & & & 25.93 & & & & & & \\
\hline \multirow{2}{*}{$\begin{array}{c}\text { VLDL- } \\
\text { C }\end{array}$} & $\mathrm{M}$ & 283 & $\begin{array}{c}26.28 \pm \\
13.37\end{array}$ & 22.2 & 9.08 & 47.72 & 7.4 & 48.2 & \\
\cline { 2 - 10 } & $\mathrm{F}$ & 136 & $\begin{array}{c}25.05 \pm \\
9.87\end{array}$ & 32 & 11.11 & 48.91 & 8 & 49.4 & \\
\hline
\end{tabular}

TC: Total Cholesterol, TG: Triglycerides, HDL-C: High-Density Lipoprotein Cholesterol, LDL-C: Low-

Density Lipoprotein Cholesterol, VLDL-C: Very Low-Density Lipoprotein Cholesterol, M: Males, F:

Females, N: Number of Samples, SD: Standard Deviations, p-value: Probability value, Significant differences considered at $\mathrm{p}$-value lower than 0.05 .

According to the age groups, the reference intervals are computed as $95^{\text {th }}$ percentiles by taking 2.5 and 97.5 percentile of each lipid profile variable (Table- 2). The results show that TC, TG, HDL-C, LDL-C, and VLDL-C levels start from 108, 40, 25, 64, and $9 \mathrm{mg} / \mathrm{dL}$, respectively, for people under 20 years old. The range continues to rise as the age of participants increases. For the 51-60 years groups, the interval starts from 117 and reaches up to $256 \mathrm{mg} / \mathrm{dL}$ for TC, which is the highest range as compared to other age groups. The minimum 2.5 percentile value for TG is $40 \mathrm{mg} / \mathrm{dL}$, recorded in the highest age group, whereas the highest 97.5 percentile value is 247 in the second highest age group. The minimum HDL-C value is recorded in the first and second age group $(25 \mathrm{mg} / \mathrm{dL})$, whereas the highest value is found in the $41-50$ years age group $(60 \mathrm{mg} / \mathrm{dL})$. The value of LDL-C starts from 56 $\mathrm{mg} / \mathrm{dL}$ for the third age group and rises to up to $173 \mathrm{mg} / \mathrm{dL}$ in the oldest (51-60 years) age group. VLDL-C value is minimum in the 21-30 years age group and maximum in the oldest age group. The results of one-way ANOVA for comparing the results among various age groups for the same variable show that the differences in between age groups are all statistically significant $(\mathrm{p}<0.05)$

Table 2- The determination of reference intervals of the lipid profile variables (TC, TG, HDL-C, LDL-C, and VLDL-C; mg/dL) according to age and gender of the study population.

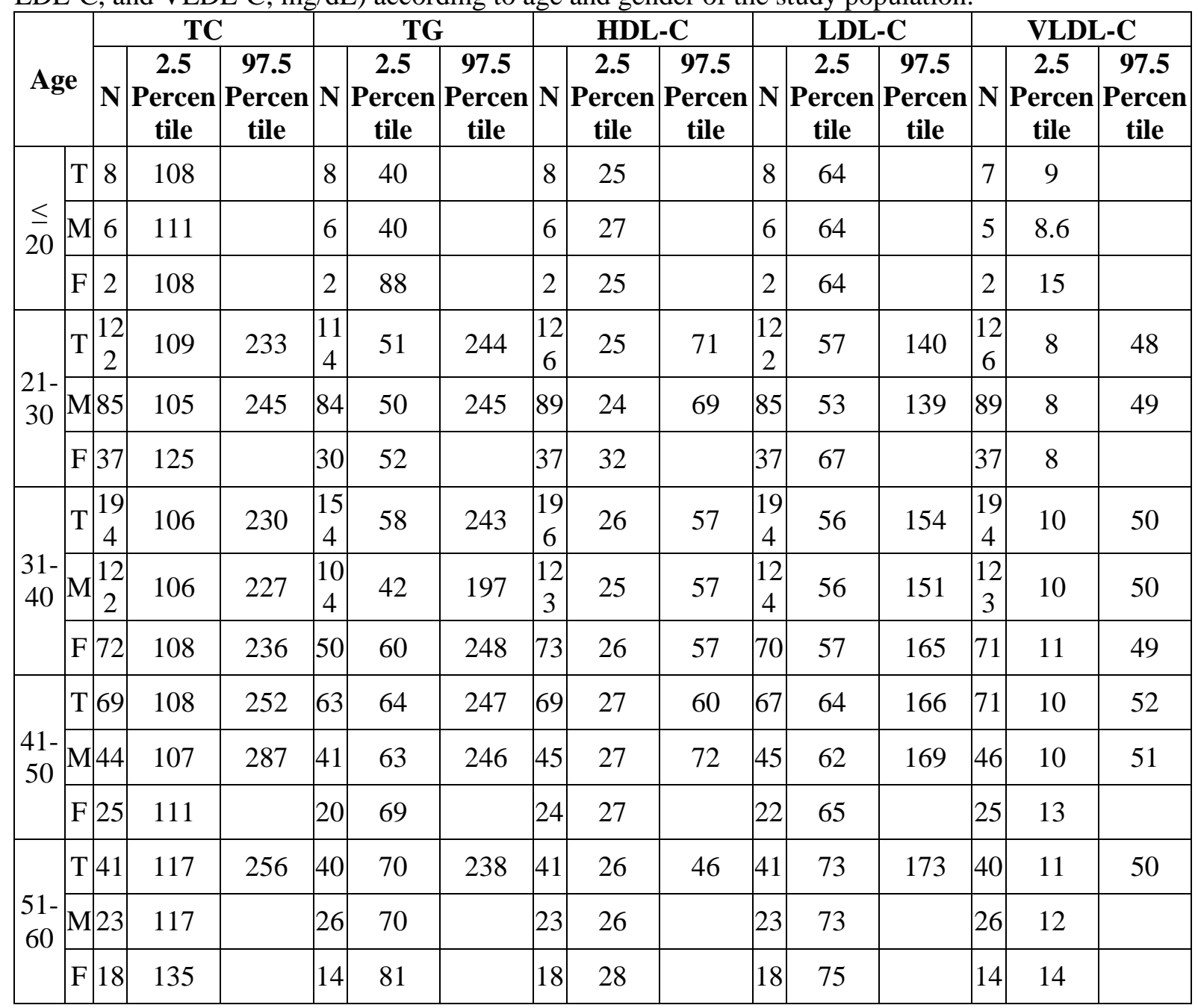




\begin{tabular}{|c|c|c|c|c|c|}
\hline $\begin{array}{c}\text { ANO } \\
\text { VA }\end{array}$ & $<.001$ & .006 & $<.001$ & $<.001$ & $<.001$ \\
\hline $\begin{array}{l}\text { TC: } \\
\text { Low } \\
\text { Males }\end{array}$ & $\begin{array}{l}\text { Cholest } \\
\text { nsity Lip } \\
\text { Females, }\end{array}$ & $\begin{array}{l}\text { iglycer } \\
\text { olester } \\
\text { : Num } \\
\text { value }\end{array}$ & $\begin{array}{l}\text { C: High } \\
\text { : Very I } \\
\text { les, AN } \\
\text { at lower }\end{array}$ & $\begin{array}{l}\text { poprotei } \\
\text { y Lipop } \\
\text { ysis of }\end{array}$ & $\begin{array}{l}\text { ol, LDL-C: } \\
\text { esterol, M: } \\
\text { gnificant p- }\end{array}$ \\
\hline
\end{tabular}

\section{Discussion}

The concept of reference intervals is established by the IFCC for achieving a better diagnosis of diseases [12]. The IFCC, Clinical Laboratory Standard Institute (CLSI), and World Health Organization (WHO) consider the reference interval as a numerical value that is resulted from quantitative testing of a precisely selected groups of people (reference population) that is subjected to specific exclusion criteria [13]. However, establishing refence intervals can vary widely between different geographical locations and populations. Many factors lead to these variations, including the environment, diet and nutrition, demographics, and genetics [14]. Thus, using reference intervals established by test kit manufacturers or by other countries and populations can lead to misdiagnosis of diseases and possibly wrong treatment strategies of patients. The population of this study was subjected to a strict exclusion criterion, as defined by the IFCC, in order to guarantee a higher accuracy of the reference interval results. The mean calculation results of the study for various gender and age groups suggest that all lipid profile components arise as the participants get older. There is also a significant difference between the levels in both male and female groups. The results of our study are comparable with many other studies from the literature $[15,16]$. It is noteworthy that females have slightly higher mean lipid profile values than males in almost all various lipid components of our study. Similar results to this could be seen across the literature [15]. The reference intervals for various age groups and both genders are estimated from the reference distribution by taking $2.5^{\text {th }}$ and $97.5^{\text {th }}$ percentile from the overall test result values (observed values) of each variable. For TC, there is a significant difference $(\mathrm{p}=0.007)$ between male and female adults of the reference population, where females have higher rates of TC than their male counterparts. Close to our results are those observed in Iranian female adults in a study by Jalali et al.; however, the mean TC value of our study population is lower than that of the Iranian adults [7]. In TG, as well as TC, the mean values in females are higher than those in males; however, the difference is not statistically significant $(\mathrm{p}=$ 0.247). Our result is different from that in the Iranian adults who recorded lower TG values in females [7]. However, our results are close to those reported for the Indian adult population in terms of TG value distribution between males and females [9]. The values of HDL-C showed no significant differences between the genders. Upon the comparison of LDL-C mean values between the two genders, a slightly significant difference (p-value of 0.049 ) is obtained.. The ranges are slightly higher in females than males, which indicate comparable results to the Indian and African populations, while reciprocal to the Iranian population studies [7-9]. The VLDL-C is a factor of TG and, thus, the difference between the mean values in the two genders is similar to that for TG, which showed no significant difference. For the determination of reference intervals in terms of the age of reference population, the required statistics were undertaken. In the first age group, only $2.5^{\text {th }}$ percentile is computed because of the small $\mathrm{N}$ value. The TC reference interval for the youngest group starts from a value that is close to those of other older age groups, indicating that the lower reference limit for the adult population has almost the same value for various age groups. The upper limit value, on the other hand, differs from one group to another. As it might be expected, the TC intervals increase as age increases. The highest mean values and widest range values are seen in the oldest group of participants. Our results, in terms of the existence of higher levels of TC in women than men, are comparable to many studies across the literature, including the study of Gupta et al. which states gender differences in seven-year trends in the level of TC. Their study concludes that women have higher levels of TC than men and experience more hypercholesterolemia [17]. The TG reference interval for the first age group is the lowest among all other groups, indicating that the youngest population of the study has optimal ranges of TG in their blood. In a similar way to TC, the TG intervals rise as age increases. The highest mean value and widest range are seen in the fourth age group of participants. The oldest group, however, includes participants who are slightly younger than 41-50 years old. The influence of age on TG was examined in the Japanese population by a group of researchers and the results suggested that, in older females, there is a higher ratio of TG/HDL-C than that of males [18], which are similar to our 
study's observations. In a similar way to the TC variable, the lowest interval value for HDL-C in the youngest is close to that in the other elder groups. This is because the similar TC levels in those groups, which does not mean that the younger participants of the study have abnormal levels of the good cholesterol. The HDL-C upper interval value of $97.5^{\text {th }}$ percentile is seen in the second age group. The level of HDL-C in the oldest groups of participants is the converse to the levels of TC and TG, which is decreased as well. That is can be interpreted by the higher TG/HDL-C ratio in older females in the Japanese study [18]. The lowest interval values for LDL-C are also close to each other in the youngest and other elder groups, but not in the eldest. The LDL-C upper interval value, however, is seen in the oldest reference group. For VLDL-C, the age of the participants is also determinant in the range of the interval, while for the lower limit, the values are close in all younger and older groups, but the highest value is recorded in the oldest group. The differences of the lipid profile values among younger adults and elderly people of the reference population are statistically significant for all lipid components, indicating that the lipid status is a risk factor of age even in healthy adults. The values were significantly increased by the age factor. By comparing internationally accepted reference ranges to the outcomes of our study, it is safe to state that the ranges of lipid profile variables in our study's healthy population are almost similar to, or sometimes above, the internationally accepted values, as the known normal TC value is below $200 \mathrm{mg} / \mathrm{dL}$ [7], while our adult population's reference interval combining males and females with all age groups ranged $107-251 \mathrm{mg} / \mathrm{dL}$. The TG reference interval resulted from our study is $48-246 \mathrm{mg} / \mathrm{dL}$, while the accepted normal value worldwide is below 150 $\mathrm{mg} / \mathrm{dL}$ [19]. Hence, the reference community has higher than the internationally accepted values for TG. For HDL-C, the outcome of our study is almost comparable with the internationally accepted value of above $40 \mathrm{mg} / \mathrm{dL}$ [20], ranging $25-61 \mathrm{mg} / \mathrm{dL}$. LDL-C below $120 \mathrm{mg} / \mathrm{dL}$ is considered normal worldwide [21], while we observed a ranges of $58-164 \mathrm{mg} / \mathrm{dL}$, which is again higher than the known reference values. VLDL-C levels at less than $40 \mathrm{mg} / \mathrm{dL}$ are considered normal [7], while we observed the interval range of $9-48 \mathrm{mg} / \mathrm{dL}$. The outcomes of this study are important for a better understanding of the statues of Halabja city's population in terms of their lipid profile. These outcomes can help in better diagnosis of people facing risks of developing dyslipidaemia complications. It is suggested that our results need to be considered in clinical practice in Halabja city as they present locally established reference intervals based on Halabja's adult population. However, there are some limitations of this study that need to be looked at. One limitation is that only adults were included (aged 18-60 years), because the population selected for conducting the study consisted of public sector employees who are all adults. Also, the sample size is relatively small. For a better establishment of the reference intervals, thousands of participants need to be included. Besides, in our study's population, the subgroups were not equally distributed. Another limitation is regarding the dietary status of the reference population, which was not surveyed or controlled prior to the study, although all reference individuals were at overnight fasting during the specimen collection.

\section{Conclusions}

As the clinical diagnosis of diseases is basically based on the test results, the interpretation of which is achieved by comparing the outcome to the well-known, trusted, and standard reference intervals, the more realistic and inclusive the reference intervals be, the better the clinical diagnosis that will be achieved. In this study, we established reference intervals for the lipid profile of the adult population of the Halabja city for the first time. The results of the study propose that the currently used reference intervals for lipid profile test are not quite representing the actual reference intervals of the healthy asymptomatic adult population of Halabja. Hence, it is more convenient and trustful to use the outcomes of our study which are the only locally established reference intervals rather than the currently used ones in the clinical practice.

\section{References}

1. G. Jones and A. Barker, Aug. 2008. Reference intervals, Clin. Biochem. Rev., 29(Suppl 1): S93S97, [Online]. Available: https://pubmed.ncbi.nlm.nih.gov/18852866.

2. G. D. C. et al., Feb. 2006. Dyslipidemia Prevalence, Treatment, and Control in the Multi-Ethnic Study of Atherosclerosis (MESA), Circulation, 113(5): 647-656, doi: 10.1161/ CIRCU LAT ION AHA. 105.552737.

3. S. I. Hameed, A. W. Al-Shahwany, and S. J. Salih, Dec. 2019. Investigation the potential role of some medicinal plants extracts in regulating serum lipid profile in female albino rats, Iraqi J. Sci., 
60(12): 2561-2571, [Online]. Available: http://scbaghdad.edu.iq/eijs/index.php /eijs/article /view $/ 1281$.

4. Okrainec K, B. DK, and E. MJ, 2004. Coronary artery disease in the developing world., Am Hear. J., 148(1): 7-15, doi: https://doi.org/10.1016/j.ahj.2003.11.027.

5. WHO, 2018. The top 10 causes of death, https://www.who.int/news-room/fact-sheets/detail/thetop-10-causes-of-death (accessed Aug. 03, 2020).

6. M. M. F. Al. Halbosiy, M. K. Ismael, and H. A. Nasser, Oct. 2019. Correlation Between Chlamydia pneumoniae Infection and Lipid Profile in Patients with Cardiovascular Diseases, Iraqi J. Sci., 60(10): 2129-2135, [Online]. Available: http://scbaghdad.edu.iq/eijs /index.php/eijs /article/view/1186.

7. M. T. Jalali, A. M. Honomaror, A. Rekabi, and M. Latifi, 2013. Reference ranges for serum total cholesterol, HDL-cholesterol, LDL-cholesterol, and VLDL-cholesterol and triglycerides in healthy iranian ahvaz population, Indian J. Clin. Biochem., 28(3): 277-282, doi: 10.1007/s12291-0120268-x.

8. P. Durgawale, S. Patil, P. S. Shukla, A. Sontakke, S. Kakade, and S. Yadav, 2009. Evaluation of reference intervals of serum lipid profile from healthy population in western maharashtra," $\mathbf{2 4}(1)$ : $30-35$,

9. B. Faso, A. T. C. R. K. Koumaré, L. P. L. Sakandé, E. Kabré, and I. Sondé, 2015. Reference Ranges of Cholesterol Sub- Fractions in Random Healthy Adults in," pp. 1-8, doi: 10.1371/journal.pone.0116420.

10. F. Q. Nuttall, 2015. Body Mass Index: Obesity, BMI, and Health: A Critical Review, Nutr. Today, 50(3): 117-128.

11. V. Kaur, M. Verma, and A. Kaur, 2012. To Establish the Reference Intervals of Lipid Profile in Punjab, 27(176): 290-295, doi: 10.1007/s12291-012-0208-9.

12. H. E. Solberg, Sep. 1993. A guide to IFCC recommendations on reference values., J. Int. Fed. Clin. Chem., 5(4): 162-165.

13. S. H., 1987. International Federation of Clinical Chemistry Expert panel on theory of reference Values: Part I- The concepts of Reference values, J Clin Chem Clin Biochem, 25: 337-42, 639-44.

14. N. Slhessarenko and A. Andriolo, 2016. The importance of determining reference intervals for Laboratory Medicine, J. Bras. Patol. e Med. Lab., 52,(Apr)., doi: 10.5935/1676-2444.20160019.

15. C. Odhiambo et al., Apr. 2015. Evaluation of locally established reference intervals for hematology and biochemistry parameters in Western Kenya, PLoS One, 10(4): e0123140e0123140, doi: 10.1371/journal.pone.0123140.

16. P. Zhao, S. Liu, Z. Zhong, and J. Liu, Jun. 2018. Age- and sex-related difference of lipid profile in patients with ischemic stroke in China, Medicine (Baltimore)., 97(23): e10930-e10930, doi: 10.1097/MD.0000000000010930.

17. R. Gupta, M. Sharma, N. K. Goyal, P. Bansal, S. Lodha, and K. K. Sharma, 2016. Gender differences in 7 years trends in cholesterol lipoproteins and lipids in India: Insights from a hospital database, Indian J. Endocrinol. Metab., 20(2): 211-218, doi: 10.4103/2230-8210.176362.

18. I. Wakabayashi, 2012. Influence of age and gender on triglycerides-to-HDL-cholesterol ratio (TG/HDL ratio) and its association with adiposity index, Arch. Gerontol. Geriatr., 55(3): 729-734, doi: 10.1016/j.archger.2012.07.001.

19. L. Berglund et al., 2012. Evaluation and treatment of hypertriglyceridemia: An endocrine society clinical practice guideline, J. Clin. Endocrinol. Metab., 97(9): 2969-2989, doi: 10.1210/jc.20113213.

20. T. Malati and M. R. U. Mahesh, 2009. Reference intervals for serum total cholesterol, HDLcholesterol, LDL-cholesterol, triglycerides, Lp (a), apolipoprotein A-I, A-II, B, C-II, C-III, and E in healthy South Indians from Andhra Pradesh, Indian J. Clin. Biochem., 24(4): 343-355, doi: 10.1007/s12291-009-0063-5.

21. W. Hao and A. Friedman, 2014. The LDL-HDL profile determines the risk of atherosclerosis: A mathematical model, PLoS One, 9(3), doi: 10.1371/journal.pone.0090497. 